\title{
Autonomia do idoso e suas implicações éticas na assistência de enfermagem
}

\author{
Autonomy of the elderly and its ethical implications on nursing care

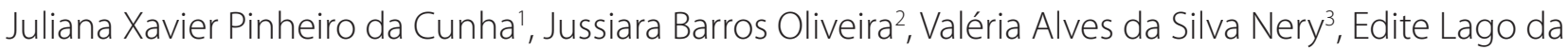 \\ Silva Sena ${ }^{4}$, Rita Narriman Silva de Oliveira Boery ${ }^{5}$, Sergio Donha Yarid ${ }^{6}$
}

\author{
1 Mestranda do Programa de Pós-Graduação \\ Enfermagem e Saúde da Universidade \\ Estadual do Sudoeste da Bahia (UESB) - \\ Itapetinga (BA), Brasil. \\ julianaxcunha@gmail.com \\ ${ }^{2}$ Mestranda do Programa de Pós-Graduação \\ Enfermagem e Saúde da Universidade \\ Estadual do Sudoeste da Bahia (UESB) - \\ Itapetinga (BA), Brasil. \\ sarah_disc@hotmail.com \\ ${ }^{3}$ Mestranda do Programa de Pós-Graduação \\ Enfermagem e Saúde da Universidade \\ Estadual do Sudoeste da Bahia (UESB) - \\ Itapetinga (BA), Brasil. \\ valalves04@yahoo.com.br \\ ${ }^{4}$ Doutora em Enfermagem pelo Programa \\ de Pós-Graduação em Enfermagem da \\ Universidade Federal de Santa Catarina \\ (UFSC) - Florianópolis (SC), Brasil. Professora \\ do Departamento de Saúde e do Programa \\ de Pós-graduação em Enfermagem e Saúde \\ da Universidade Estadual do Sudoeste \\ da Bahia (UESB) - Itapetinga (BA), Brasil. \\ editelago@gmail.com \\ ${ }^{5}$ Doutora em Enfermagem pela Universidade \\ Federal de São Paulo (UNIFESP) - São Paulo \\ (SP), Brasil. Professora do Departamento de \\ Saúde e do Programa de Pós-graduação \\ em Enfermagem e Saúde da Universidade \\ Estadual do Sudoeste da Bahia (UESB) - \\ Itapetinga (BA), Brasil. \\ rboery@gmail.com \\ ${ }^{6}$ Doutor em Odontologia Preventiva e \\ Social pela Universidade Estadual Paulista \\ (UNESP) - São Paulo (SP), Brasil. Professor \\ do Departamento de Saúde e professor \\ convidado do Programa de Pós-graduação \\ em Enfermagem e Saúde da Universidade \\ Estadual do Sudoeste da Bahia (UESB) - \\ Itapetinga (BA), Brasil. \\ syarid@hotmail.com
}

RESUMO Objetiva-se analisar a literatura existente sobre a preservação dos aspectos éticos da autonomia da pessoa idosa e as implicações na assistência de enfermagem. A busca foi realizada através da Biblioteca Virtual em Saúde, no período de 2003 a 2011. Da análise emergiram três eixos temáticos: Visão social sobre o idoso; O princípio ético da autonomia para o idoso; e O respeito à autonomia na assistência de Enfermagem ao idoso. Conclui-se que a promoção e a preservação da autonomia do idoso são fundamentais na assistência de enfermagem, visando a garantir atenção integral e a proporcionar participação ativa e cidadã do idoso, enquanto sujeito individual e coletivo.

PALAVRAS CHAVE: Idoso; Autonomia pessoal; Cuidados de enfermagem; Ética.

ABSTRACT The objective is to analyze the existing literature on the preservation of ethical autonomy of older people and the implications for nursing care. The search was performed using the Virtual Health Library, from 2003 to 2011. Three issues came up from the analysis: social vision on the elderly; the ethical principle of autonomy for the elderly; and Respect for autonomy in nursing care for the elderly. It concludes that the promotion and preservation of the independence of older people are fundamental to nursing care in order to ensure comprehensive care and provide active participation and citizen of the elderly, while individual and collective subject.

KEYWORDS: Elderly; Personal autonomy; Nursing care; Ethics. 


\section{Introdução}

O estudo sobre a autonomia do idoso e suas implicaçóes éticas buscou encontrar subsídios que pudessem favorecer a reflexão dos aspectos éticos na assistência de enfermagem à pessoa idosa, frente à necessidade de preservação de sua autonomia.

No Brasil, a transição demográfica vivenciada nas últimas décadas vem delineando uma condição que já desperta preocupação: a população está envelhecendo. Atualmente, a população brasileira de idosos representa um contingente de quase 21 milhóes de pessoas, com 60 anos ou mais de idade, e estima-se que, em 2050, os idosos corresponderão a $22,71 \%$ da população total (IBGE, 2008).

Esse novo cenário nacional exige do Estado formulação e implementação de políticas públicas que assistam essa população e, especialmente, de um sistema de saúde que esteja preparado para atender às especificidades dessa demanda. Para tanto, deverá contar com profissionais que compreendam o processo de envelhecer em todas as suas dimensôes (biológicas, sociais, psicológicas e espirituais), respeitando a autonomia que o idoso possui sobre o seu cuidado.

Considerando o impacto do envelhecimento nas políticas públicas, o governo brasileiro tem aprovado leis voltadas para o envelhecimento ativo e saudável. Com essa finalidade, foi aprovada a Política Nacional de Saúde da Pessoa Idosa - PNSPI, que tem como um de seus objetivos a promoção da autonomia, independência, integração e participação efetiva do idoso na sociedade, com vistas ao exercício da cidadania e ao atendimento de suas necessidades específicas, nos diversos níveis de atenção do SUS (BRASIL, 2006). Assim, é necessário que qualquer política destinada à população idosa leve em conta, entre outros aspectos, a necessidade de preservação da autonomia (VERAS, 2009).

Entende-se que promover o envelhecimento ativo e saudável significa prevenir a perda da capacidade funcional da população idosa, através da preservação da sua independência física e psíquica, promovendo o bemestar físico, mental e social, bem como garantir o acesso a instrumentos diagnósticos adequados, medicação e reabilitação funcional (BRASIL, 2006).
A autonomia é uma vertente central do envelhecimento saudável, e promover a autonomia das pessoas idosas, o direito à sua autodeterminação, mantendo a sua dignidade, integridade e liberdade de escolha é fundamental para a promoção da sua qualidade de vida (BRASIL, 2006).

No entanto, o envelhecimento está coberto de preconceitos e estereótipos, que em muito influenciam o cuidado em saúde direcionado aos idosos. Em muitas situaçóes do cotidiano dos serviços de saúde, observase que os profissionais menosprezam a capacidade de decisão do idoso, fornecendo informações superficiais sobre seu tratamento e diagnóstico, adotando, assim, uma postura paternalista, impedindo-o de exercer a autonomia para decidir sobre o que acha melhor para seu cuidado.

Diante disso, os profissionais de saúde, na sua prática, deparam-se com situaçóes éticas que os levam a um confronto de seus princípios e valores com os dos pacientes e familiares, por serem situaçóes dilemáticas e polêmicas, fazendo com que os valores dos profissionais determinem suas açóes (SANTOS; MASSAROLLO, 2004).

O profissional de enfermagem, por disponibilizar mais tempo para o cuidado ao idoso, depara-se constantemente com problemas e dilemas éticos durante o cuidado prestado a esses pacientes, dentre os quais se encontra a necessidade de respeito à sua autonomia. Sendo assim, faz-se necessário que, na sua atuação, a postura profissional, a atitude ética e o cuidado ao paciente não sejam dissociados (VISENTIN; LABRONICI; LENARDT, 2007).

O Código de Ética dos Profissionais de Enfermagem prevê o exercício da profissão assegurando à pessoa ou à comunidade informaçóes sobre a assistência prestada ou planejada, sem distinção de raça, credo ou idade, reconhecendo a capacidade cognitiva e emocional na relação estabelecida no cuidado (CONSELHO, 2007). Portanto, a postura ética do profissional de enfermagem deve observar os aspectos éticos na assistência à pessoa idosa.

Historicamente, nas relações de cuidado em saúde, tem prevalecido a postura paternalista. Nessa concepção, as decisões são unilaterais e, geralmente, o 
profissional de saúde decide a respeito do que é melhor para o paciente. Essas atitudes predominam de forma acentuada nas práticas dos profissionais no cuidado aos idosos, por julgarem serem estes incapazes de decidir de forma sensata a respeito de sua saúde. Nesse sentido, pode ser afetado um dos princípios básicos da bioética, que é o respeito à autonomia.

O respeito ao princípio da autonomia na assistência ao idoso deve levar o profissional de saúde, em particular o da enfermagem, a considerar a capacidade de escolha, crenças e valores morais do paciente. Isso possibilita que o idoso exerça a sua autonomia e decida entre as alternativas de cuidado que lhe são apresentadas, a partir da compreensão clara das consequências de cada uma delas.

Dessa forma, busca-se, com este artigo, analisar a literatura existente sobre a preservação dos aspectos éticos da autonomia da pessoa idosa e as implicaçôes na assistência de enfermagem.

\section{Método}

Trata-se de uma revisão de literatura, realizada no primeiro semestre de 2011, buscando-se responder as seguintes questóes norteadoras: o que a literatura eletrônica apresenta acerca da preservação dos aspectos éticos da autonomia da pessoa idosa? Quais as implicações da preservação dessa autonomia para a assistência de enfermagem?
Para isso, foram realizadas buscas na Biblioteca Virtual em Saúde - BVS, em publicaçóes compreendidas entre os anos de 2003 e 2011. A delimitação do recorte temporal da pesquisa teve por início o ano de 2003, por ter sido o ano em que foi decretado e sancionado o dispositivo legal de incentivo à preservação da autonomia dos idosos brasileiros, a Lei No 10.741/ 2003, que aprovou o Estatuto do Idoso (BRASIL, 2003).

Para seleção dos estudos, realizou-se uma análise prévia a partir da leitura dos títulos e resumos, a fim de verificar se preenchiam os critérios de inclusão estabelecidos: estudos completos em português, publicados a partir de 2003, que se adequassem a uma das questóes norteadoras. Foram excluídos: conferências, capítulos de livros, assim como pesquisas que não tivessem relação com a temática proposta.

Surgiram 85 estudos distintos a partir da uniāo entre descritores: "idoso"; "autonomia pessoal"; "cuidado de Enfermagem"; "ética" e "Enfermagem". Porém, ao se aplicarem os critérios de inclusão e exclusão, foram selecionadas 12 pesquisas que se aproximaram do objetivo proposto. Essas foram salvas em arquivos doc e $p d f$, e armazenadas em pasta própria, analisadas criteriosamente, identificadas conforme foco de investigação e objetivo do estudo.

Para nortear a discussão, foram identificados três eixos temáticos: visão social sobre o idoso; o princípio ético da autonomia para o idoso; e o respeito à autonomia na assistência de Enfermagem ao idoso.

Tabela 1. Estudos que contemplam a autonomia da pessoa idosa, publicados no período de janeiro de 2000 a junho de 2011 $(\mathrm{N}=12)$

\begin{tabular}{|c|c|c|c|}
\hline Autor/ Ano & Sujeitos & Método/ coleta dos dados & Tipo de pesquisa \\
\hline ALMEIDA; AGUIAR/ 2011 & $\begin{array}{l}\text { Enfermeiros que cuidam de } \\
\text { idosos hospitalizados }\end{array}$ & Entrevista & Qualitativa \\
\hline TAMAI / 2011 & Idosos & Questionário & Quantitativa \\
\hline FERNANDES; GARCIA/2010 & Mulheres idosas & Entrevistas & Qualitativa \\
\hline FLORES / 2010 & $\begin{array}{c}\text { Idosos e seus respectivos } \\
\text { cuidadores }\end{array}$ & Observação e entrevista & Qualitativa \\
\hline
\end{tabular}




\begin{tabular}{|c|c|c|c|}
\hline Autor/ Ano & Sujeitos & Método/ coleta dos dados & Tipo de pesquisa \\
\hline OLIVEIRA; ALVES/ 2010 & ------------------ & 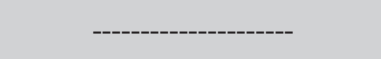 & Revisão bibliográfica \\
\hline $\begin{array}{l}\text { VISENTIN; LABRONICl; } \\
\text { LENARDT/ } 2007\end{array}$ & 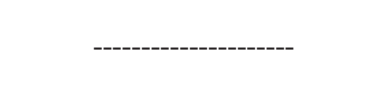 & ----. & Revisão bibliográfica \\
\hline REIS; CEOLIM/ 2007 & $\begin{array}{l}\text { Trabalhadores que prestam } \\
\text { cuidados de enfermagem } \\
\text { a idosos institucionalizados }\end{array}$ & Questionário & Quantitativa \\
\hline $\begin{array}{l}\text { GANDOLPHO; FERRARI/ } \\
2006\end{array}$ & 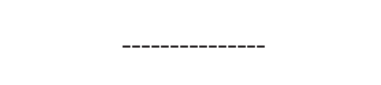 & --------------- & Revisão bibliográfica \\
\hline & 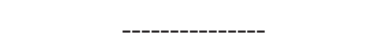 & 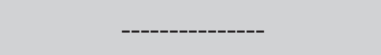 & Revisão bibliográfica \\
\hline $\begin{array}{l}\text { MARTINS; RODRIGUES/ } \\
2004\end{array}$ & . & -..- & Revisão bibliográfica \\
\hline SANTOS; EIDT/ 2004 & & 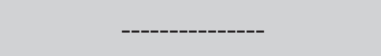 & \\
\hline $\begin{array}{l}\text { SANTOS; MASSAROLLO/ } \\
2004\end{array}$ & Enfermeiros & Entrevista & Quanti-qualitativa \\
\hline ALVES JÚNIOR/ 2004 & $\begin{array}{l}\text { Idosos coordenadores e } \\
\text { responsáveis por duas } \\
\text { associações brasileiras e } \\
\text { duas francesas }\end{array}$ & Observação e entrevista & Qualitativa \\
\hline
\end{tabular}

Fonte: ALMEIDA; AGUIAR, 2011; TAMAI , 2011; FERNANDES; GARCIA, 2010; FLORES et al, 2010; OLIVEIRA; ALVES, 2012; VISENTIN; LABRONICl; LENARDT, 2007; REIS; CEOLIM, 2007; GANDOLPHO; FERRARI, 2006; MARTINS; RODRIGUES, 2004; SANTOS; EIDT, 2004; SANTOS; MASSAROLLO, 2004; ALVES JÚNIOR, 2004.

\section{Resultado e Discussão}

Dos estudos analisados, $42 \%(\mathrm{~N}=5)$ foram classificados como sendo de revisão bibliográfica, e $58 \%(\mathrm{~N}=7)$ foram pesquisas originais. Dentre as pesquisas originais, $43 \%(\mathrm{~N}=3)$ se enquadraram como qualitativas, tendo a mesma porcentagem os estudos de abordagem quantitativa. Apenas 14\% (N=1) foram classificados como sendo de abordagem quanti-qualitativa.

Dentre as pesquisas originais, a entrevista foi o método de coleta de dados mais utilizado, estando presente em 57\% ( $\mathrm{N}=4)$. Além disso, 2 desses estudos utilizaram a entrevista associada à observação, a fim de contemplar os objetivos propostos pela pesquisa.
Com relação ao ano de publicação dos estudos, verificou-se uma maior concentração em 2004, 33\% $(\mathrm{N}=4)$, e $25 \%(\mathrm{~N}=3)$ em 2010. Porém, como esta pesquisa se processou até o primeiro semestre de 2011, pode ser que ao longo desse ano tenham ocorrido mais publicaçôes referentes à temática.

Em se tratando da adequação às questōes norteadoras, $67 \%(\mathrm{~N}=8)$ das pesquisas responderam as duas questōes estipuladas como foco do objeto de pesquisa deste artigo: o que a literatura eletrônica apresenta acerca da preservação dos aspectos éticos da autonomia da pessoa idosa? Quais as implicações da preservação dessa autonomia para a assistência de enfermagem? E 33\% $(\mathrm{N}=4)$ responderam apenas a primeira questão, assim, 
buscou-se nesses estudos a compreensão dos estereótipos que cercam a pessoa idosa e as implicaçóes para a sua autonomia, a fim de contribuir para a discussão frente à assistência de Enfermagem ao idoso.

A partir da análise, emergiram três categorias sobre a autonomia do idoso e as suas implicaçôes éticas na assistência de enfermagem, que serão discutidas a seguir.

\section{Visão social sobre o idoso}

Foram identificados, na revisão de literatura, que os estereótipos sociais da velhice sempre estiveram ligados à degradação biológica e cognitiva. Muitas vezes, o idoso é visto como improdutivo e dependente, não sendo capaz de desempenhar, de forma eficaz, qualquer função, seja com relação às áreas profissionais e sexuais, seja com relação ao exercício do seu autocuidado (REIS; CEOLIM, 2007).

Dessa maneira, a população tende a desconsiderar os valores dos idosos, não aceitando seus julgamentos e críticas, rotulando-os como pessoas submissas e que possuem uma capacidade diminuída de desfrutar os prazeres da vida (FERNANDES; GARCIA, 2010).

Além disso, em muitas situações, a velhice é representada como um retorno à infância. $\mathrm{O}$ tratamento que é destinado aos idosos, por vezes, apresenta expressóes infantis e de menosprezo à sua capacidade de compreensão. Essa aproximação entre infância e velhice acaba por fortalecer ainda mais a concepção de dependência da pessoa idosa (ALVES JUNIOR, 2004).

Essa visão social deturpada a respeito dos idosos resulta do entendimento que a sociedade tem do envelhecimento como um processo que torna as pessoas senis, inativas, fracas e inúteis. Socialmente, esse posicionamento preconceituoso frente ao idoso é resultado de uma representação social gerontofóbica, o que influencia em vários aspectos a vida dos idosos e a visão que eles têm de si mesmos (MARTINS; RODRIGUES, 2004).

No que se refere ao cuidado à saúde, a concepção de que o idoso é um "adulto menos capaz" muitas vezes impera, e isso resulta de um desconhecimento dos seus aspectos fisiológicos, psicológicos, emocionais e sociais, o que gera, muitas vezes, um atendimento inadequado (REIS; CEOLIM, 2007).

Desta maneira, o cuidado ao idoso fica comprometido quando é fundamentado em uma visão social generalista e preconceituosa, que desconsidera as características individuais da pessoa idosa. Frente a isso, é necessário que o tratamento destinado a essa população seja especializado e livre de associaçóes estigmatizantes, o que possibilita ao idoso o exercício de sua autonomia (TAMAI , 2011).

\section{O princípio ético da autonomia para o idoso}

Para os autores estudados, a autonomia é um dos princípios da Bioética utilizado para análises de dilemas el ou conflitos de valores nos relacionamentos humanos, os outros princípios são o da justiça, o da beneficência e o da náo maleficência. $\mathrm{O}$ termo autonomia é derivado do grego autos (próprio, eu) e nomos (regra, domínio, governo, lei), significando o poder de tomar decisóes sobre si mesmo e assumir o controle de sua vida. Portanto, inclui noçáo de autogoverno, liberdade de direitos, escolha individual, agir segundo a própria pessoa (OLIVEIRA; ALVES, 2010).

$\mathrm{O}$ respeito à autonomia pressupóe a oferta de informaçóes e a obtenção do consentimento informado do idoso, através da manifestação de sua vontade, sem ter sido submetido à coação, influência, indução ou intimidação (ALMEIDA; AGUIAR, 2011). Os autores destacam que, para a autonomia ser respeitada, deve-se levar em consideração que as decisóes adotadas pelos idosos estarão embasadas nos seus princípios e valores, sendo que o profissional precisa respeitá-las.

Conduta dessa natureza fortalece as relações democráticas, e, na falta de informação, prevalece a ignorância e abrem-se brechas para que sejam realizadas ações abusivas, de exploração, subjugação e dominação (SANTOS; EIDT, 2004). Desse modo, é necessário que as pessoas tenham conhecimento sobre seu estado de saúde, a fim de que, bem informadas, lutem pelos seus ideais e crenças e possam exercer o governo sobre sua vida. 
Muitas vezes, os profissionais de saúde não valorizam o direito que o paciente tem de ser informado, pois, estando mais esclarecido, fará reivindicações e não aceitará atitudes paternalistas. Com relação aos idosos, outro fator que dificulta o acesso às informações está relacionado aos estereótipos sociais que influenciam a prática do profissional no cuidado à pessoa idosa; essa, por sua vez, não pode ser anulada e tampouco ter o seu direito à informação desrespeitado, em função de estereótipos sociais que generalizam os idosos como incapazes e dependentes; o fato de tratá-lo como uma pessoa que tem o direito de exercer a sua autonomia possibilita uma relação respeitosa entre o idoso e o profissional (VISENTIN; LABRONICI; LENARDT, 2007).

Existe, enraizada na prática de muitos profissionais, a visão de que a autonomia do idoso está diretamente associada à noção de dependência social e física. Eles desconsideram o idoso como participante de seu processo de vida e adoecer e o direito de ter conhecimento sobre sua condição de saúde, aspectos que interferem na tomada de decisóes pautadas na autonomia; enfim, adotam uma atitude paternalista (VISENTIN; LABRONICI; LENARDT, 2007).

O paternalismo é definido como condutas realizadas pelos profissionais que, julgando beneficiar o paciente, decidem por ele sem o seu consentimento. Em se tratando de pessoas idosas, que estejam com suas capacidades cognitivas preservadas, a atitude paternalista infringe uma regra ética, legal e moral (SANTOS; MASSAROLLO, 2004).

Vale ressaltar que os idosos que se identificam como autônomos sentem-se mais valorizados e com a dignidade preservada; e, para eles, a falta de respeito à sua autonomia reflete diretamente na sua qualidade de vida. Mesmo que haja algum tipo de dependência, a autonomia pode ser vivenciada no cotidiano do idoso, a partir do momento em que os profissionais consideram as suas escolhas e lhe dão liberdade para agir (FLORES, 2010).

\section{$O$ respeito à autonomia na assistência de En- fermagem ao idoso}

Os estereótipos com relação aos idosos, construídos socialmente, por vezes, permeiam as ações de enfermagem e configuram-se elementos impeditivos para que esses pacientes possam gerenciar o seu cuidado. Isso faz com que as pessoas idosas tornem-se dependentes dos profissionais que cuidam de sua saúde e que decidem a respeito dela, e, por falta de preparo, muitas vezes, tais profissionais tendem a infantilizar o cuidado.

$\mathrm{O}$ tratamento infantilizado do idoso resulta de uma comparação equivocada do tratamento afetivo e respeitoso que é dado às crianças, concepção que aproxima velhos e crianças e que, por vezes, é inculcado no imaginário social. Isso pode ser resultado, em parte, da aparente fragilização e dependência dessa população, o que acaba por se manifestar na prática dos profissionais de enfermagem, no sentido de atuar de forma imperativa, não respeitando as decisóes do idoso e nem lhe fornecendo informaçôes suficientes sobre sua saúde (ALVES JUNIOR, 2004).

Ao agir dessa forma, o profissional acaba por vitimizar os idosos, ao utilizar expressóes diminutivas e infantilizadoras, acreditando que assim estará demonstrando afeto e compaixão. Muitas vezes, esses aspectos se apresentam de forma velada na prática cotidiana do profissional de enfermagem, no momento em que concebe todo idoso como uma pessoa dócil, submissa e conformada, o que, na verdade, contribui para que se diminua ainda mais a sua autonomia e independência (REIS; CEOLIM, 2007).

Quando o profissional desrespeita a autonomia do idoso, ele o submete a seus cuidados de forma autoritária, fazendo com que muitos idosos apresentem um comportamento passivo e pouco questionador; ao contrário, é fundamental que a equipe de enfermagem preserve a capacidade de decisão do idoso, garanta o cuidado sob a perspectiva da integralidade e estabeleça um vínculo que resulte em uma assistência respeitosa e digna; é imprescindível valorizar suas vivências e contribuiçôes, tratá-lo com atenção, amabilidade, paciência, atendendo às suas necessidades biopsicossociais com competência, estimulando o autocuidado, contribuindo para sua independência e autonomia (GANDOLPHO; FERRARI, 2006).

Dessa forma, ao prestar assistência de enfermagem às pessoas idosas, não se deve rotulá-las como incapazes, pois o envelhecimento apresenta-se a cada ser humano 
de forma singular, e, para os que necessitam de cuidados mais constantes, na medida do possível, deve ser estimulado o autocuidado e considerada a capacidade de decisão.

É necessário rejeitar concepçóes negativas sobre o envelhecer e, mesmo para aqueles idosos mais fragilizados, é necessário que o cuidado esteja fundamentado na manutenção de sua autonomia e da qualidade de vida (SANTOS; EIDT, 2004). Diante disso, os profissionais de enfermagem precisam rever seus conceitos sobre o ser idoso, com o intuito de desenvolver suas atividades de forma a promover a independência e garantir a autonomia, tendo como meta a atenção holística ao ser humano que envelhece.

O profissional de enfermagem precisa estar consciente de que é fundamental uma avaliação constante para motivar a autonomia do idoso, pois os cuidados devem ser reestruturados conforme o estado de saúde apresentado, para que ele participe do gerenciamento de seu cuidado de maneira segura.

Assim, a assistência deve se efetivar através de uma avaliação multidimensional do idoso por parte do enfermeiro e de outros profissionais da equipe de saúde, visando à participação ativa do idoso no seu cuidado, incentivando sua autonomia e corresponsabilidade. Essa conduta inscreve-se em uma atitude ética, o que se contrapôe à instituição social de estereótipos e atitudes paternalistas que interferem no cuidado.

Ao adotar uma postura paternalista, o profissional não valoriza a capacidade de decisão dos idosos de exercer seu autogoverno. Um exemplo disso é a omissão total ou parcial para o paciente sobre seu estado de saúde, principalmente quando o prognóstico não lhe é favorável, e a situação se mostra mais frequente quando se trata de pessoas idosas (SANTOS; MASSAROLLO, 2004). Geralmente, o profissional, no intuito de proteger o idoso, no caso da constatação de uma patologia, não lhe informa o diagnóstico, o que fere o princípio ético da autonomia. Dessa forma, o profissional fica diante de situaçóes dilemáticas, como, por exemplo, comunicar ou não à pessoa idosa uma enfermidade terminal ou que o seu tratamento é apenas paliativo (SANTOS; MASSAROLLO, 2004; VISENTIN; LABRONICI; LENARDT, 2007).
Porém, nem sempre é possível que o idoso gravemente enfermo ou com limitaçóes cognitivas compreenda as informaçóes que lhe são fornecidas sobre o seu estado de saúde. Nesses casos, em que a autonomia encontra-se comprometida, as relaçôes da equipe de saúde ocorrem com a família. Assim, por exemplo, para a decisão da continuidade de um tratamento, a escolha deve considerar a opção demonstrada pela pessoa idosa antes do comprometimento; dessa forma, tenta-se resguardar a sua autonomia (VISENTIN; LABRONICI; LENARDT, 2007).

Portanto, situações dilemáticas, com as quais o profissional de enfermagem se depara na assistência ao idoso, devem ser analisadas sob a perspectiva da bioética, em suas várias vertentes. Caso o respeito à autonomia do idoso infrinja outros princípios éticos da beneficência, da justiça e da não-maleficência, o profissional deve rever a sua atuação, a fim de prestar uma assistência de enfermagem qualificada e racional, garantindo a integridade física, espiritual e emocional da pessoa idosa.

\section{Considerações Finais}

O profissional de enfermagem deve estar a todo o momento revendo a sua postura ética no cuidado à pessoa idosa, pois os estereótipos sociais constantemente interferem nas práticas desses profissionais, fazendoos adotar uma atitude paternalista e, de certa forma, autoritária. A partir do momento em que o princípio ético da autonomia dessa população for respeitado na assistência de enfermagem, contribuirá para a participação ativa e cidadã no seu processo de cuidado.

Mesmo para as pessoas idosas que se encontram em estado de saúde mais fragilizado, na medida do possível, sua autonomia deve ser estimulada por meio de açóes simples, como a escuta ativa, considerando a singularidade do envelhecimento de cada pessoa e a repercussão positiva no cuidado, a partir do momento em que lhe é garantido o direito humano básico de exercer seu autogoverno.

Verificou-se também, através da análise dos estudos, uma carência voltada para pesquisas originais 
sobre a autonomia do idoso. Ainda são poucos os estudos voltados para essa temática, que se mostra de grande relevância devido ao atual panorama brasileiro, no qual a expectativa de vida da população idosa tem aumentado e demonstrado a necessidade de haver profissionais habilitados para lidar com esse novo cenário, compreendendo o ser idoso de forma plena e ética.
Nesse sentido, este estudo poderá contribuir para uma reflexão e mudança de prática dos profissionais de enfermagem, fomentando discussóes que abordem os aspectos éticos, frente à necessidade do respeito e da preservação da autonomia do idoso, bem como estudos futuros de avaliação da assistência de enfermagem e da percepçáo dos idosos, diante dessa perspectiva de abordagem.

\section{Referências}

ALMEIDA, A.B.A.; AGUIAR, M.G.G. O cuidado do enfermeiro ao idoso hospitalizado: uma abordagem bioética. Revista bioética, Brasília, v. 19, n. 1, p. 197 - 217, 2011.

ALVES JÚNIOR, E. D. A pastoral do envelhecimento ativo. 2004. 621 p. Tese (Doutorado em Educação Física) - Universidade Gama Filho, Rio de Janeiro, 2004.

BRASIL. Lei 10.741 de 01 outubro de 2003. Dispõe sobre o Estatuto do Idoso. Brasília: DOU, 03 out. 2003.

Ministério da Saúde. Portaria n.2.528 de 01 de outubro 2006. Aprova a Política Nacional da Pessoa Idosa, 01 out. 2006, Brasília: Ministério da Saúde, 2006.

CONSELHO FEDERAL DE ENFERMAGEM. Resolução Cofen n. 311, de 8 de fevereiro de 2007. Aprova a reformulação do Código de Ética dos Profissionais de Enfermagem. Rio de Janeiro: Cofen, 2007. Disponível em: <http://www.portalcofen.gov.br/2007/ materias.asp?Article|D=7221\&sectionID=34>. Acesso em: 16 maio 2011.

FERNANDES, M.G.M.; GARCIA, L.G. O corpo envelhecido: percepção e vivência de mulheres idosas. Interface-Comunicação, Saúde, Educação, v.14, n.35, p.879-90, out./dez. 2010.

FLORES G. C. et al. Cuidado intergeracional com o idoso: autonomia do idoso e presença do cuidador. Revista Gaúcha de Enfermagem, Porto Alegre, v. 31, n.3, p. 467-74, 2010.

IBGE. Perfil dos idosos responsáveis pelos domicílios no Brasil. Rio de Janeiro: IBGE, 2008. Disponível em: <http://www.ibge.gov.br/ home/estatistica/populacao/perfilidoso/default.shtm>. Acesso em: 11 de maio 2011.

MARTINS, R.M.L.; RODRIGUES,M.L.L. Estereótipos sobre idosos: uma representação social gerontofóbica. Revista Millenium, v. 29, p. 249-54, jun. 2004.
OLIVEIRA, I. R., ALVES, V.P. A pessoa idosa no contexto da bioética: sua autonomia e capacidade de decidir sobre si mesma. Revista Kairós Gerontologia, v.13, n.2, p. 91-8, 2010.

REIS, P.O.; CEOLIM, M.F. O significado atribuído a 'ser idoso' por trabalhadores de instituições de longa permanência. Revista da Escola de Enfermagem da USP, São Paulo, v. 41, n. 1, p. 57-64, 2007.

SANTOS, L. R.; EIDT,O.R. Os direitos do cidadão usuário do Sistema Único de Saúde: um enfoque da Bioética na Saúde Coletiva. Acta Paulista de Enfermagem. v.17, n.3, p. 57-64, 2004.

SANTOS, V.D.; MASSAROLLO, M.C.K.B. Posicionamento dos enfermeiros relativo à revelação de prognóstico fora de possibilidades terapêuticas: uma questão bioética. Revista Latinoamericana de Enfermagem, Ribeirão Preto, v. 12, n. 5, p. 790-796, 2004.

TAMAI, S. A. B. et al. Impacto de um programa de promoção da saúde na qualidade de vida do idoso. Einstein, Säo Paulo, v. 9, n. 1, p. 8-13, jan./mar. 2011.

VERAS, R. Envelhecimento populacional contemporâneo: demandas, desafios e inovações. Revista de Saúde Pública, São Paulo, v. 43, n. 3, p. 548-554, 2009.

VISENTIN, A.; LABRONICl, L.; LENARDT, M.H. Autonomia do paciente idoso com câncer: o direito de saber o diagnóstico. Acta Paulistade Enfermagem, São Paulo, v. 20, n. 4, p. 509-13, 2007.

Recebido para publicação em Março/2012.

Versão definitiva em Julho/2012

Suporte financeiro: não houve

Conflito de interesse: inexistente 